\title{
Development and Evaluation of an Electrode for the Capacitive Deionization Unit
}

\author{
${ }^{1}$ Dr. V. Kalyan Raman, ${ }^{2}$ Siva Kumar Varigala, ${ }^{3}$ Prasad Nair Pariyarath \\ ${ }^{I}$ Divisional Manager \& Head, Centre of Biotechnology \& Water and Wastewater Technology, RTIC (Research \\ Technology Innovation Centre), Thermax House, 14 Mumbai Pune Road, Wakdewadi, Pune-411003, India. \\ ${ }^{2}$ Technologist, RTIC (Research Technology Innovation Centre), Thermax House, 14 Mumbai Pune Road, \\ Wakdewadi, Pune-411003, India.
}

\begin{abstract}
The existing conventional technologies like Reverse Osmosis, EDI(Electro Deionization), membrane filtration and Ultra Violet filtration offer solutions for drinking water, but various factors like capital and operational cost, ease of operation, maintenance and fouling had been the considerable driving factors to judge the techno-economic paradigm while making a technology selection. Also, the increasing demand for augmenting the safe drinking water calls for novel and sustainable breakthrough technologies. The novel and sustainable technology like Capacitive deionization (CDI) could be a potential alternative which works on electrophoretic phenomenon to provide low TDS (Total Dissolved Solids) drinking water. When water passes between a pair of carbon aerogel electrodes, ionic species are held at the charged electrode surfaces and are removed from the solution during the charging the cycle. After the electrodes become saturated with salts or impurities, the electrodes are regenerated by electrical discharge or polarity reversal, allowing the captured ions to be released into a relatively small purge stream. Thus, CDI can be used to deionize or purify water. An effort is also made to study, evaluate and compare conventional RO technology with Existing CDI technology.

Batch ion absorption studies on the newly developed electrodes recorded efficiency with ion removal of 140 ppt using 5 pairs of electrodes $\left(32 \mathrm{~m}^{2}\right.$ area) and the SEM images of the developed electrodes indicated good porosity which in turn illustrates the potential absorption capacity of the developed electrodes. The main factors to be considered while developing an ideal electrode are some of the properties like BET, electrical conductivity, capacitance, mechanical strength. Correlation studies on the comparison with RO and evaluation of the developed electrodes of the CDI were carried out.
\end{abstract}

\section{Introduction}

The desalination of seawater and brackish groundwater to provide fresh drinking water is an established and thriving industry. Desalinisation refers to any of several processes that removes amount of salt and any other minerals present in the saline water. Salt water is desalinated in order to produce fresh water that is suitable for human consumption or irrigation. The most commonly used technologies at present for the desalination process are Thermal Distillation and Reverse Osmosis (RO) filtration. This report will mainly deal with the research conducted for the development of an ideal electrode which is non-polluting, energy efficient, cost effective and electrically conductive, suitable for an industrial sized capacitive deionisation module. Capacitive Deionisation in other terms can be defined as a powerful desalination module which utilises low-pressure non membrane desalination process. Most of the existing industrial scale desalination centres get their energy from the combustion of fossil fuels, thus in effect exchange potable water for $\mathrm{CO}_{2}$ which causes global warming and eventually contributes to the demise of fresh water. As a result, global warming will lead to increase the need for additional desalination. Therefore, it is imperious to find methods to find desalination of water that are more energy efficient. Thus, electrochemical desalination tools like capacitive deionisation have the potential to be such an energy efficient technology.

The main objective of this research is to Evaluate a newly developed electrode for electro adsorption studies and its relevance for CDI technology. Capacitive Deionization technology is evaluated by taking in to consideration factors like construction, operation and maintenance costs to that of reverse osmosis and an head on head evaluation is performed. Taking into consideration brackish type feed water the cost of construction can vary accordingly depending upon various factors. Some of the major factors that influence the design development are:-

- Capacity of the water to be treated.

- Blending of source water with permeate.

- Quality of the feed. (TDS and constituents required removal required)

- Concentrate disposal.

- Pre and post treatment requirements. 
- Indirect costs.

Typical construction costs for a brackish water (Feed TDS $2000 \mathrm{mg} / \mathrm{l}$ ) membrane treatment plant, with a capacity of 3,785 Ml/d (1 mgd ) is estimated at US \$0,82/lpd (US \$3,14/gpd) (AWWA M46, 1999: 94). For the following estimate, the source water is from a natural gas well field and concentrate disposal is to a surface body of water. Site specific factors are very important and can have a huge influence on the final construction costs. For the above mentioned example ( 1 mgd brackish water treatment plant) the construction cost can be as low as US \$2 million, or as high as US \$7 depending on site specific requirements. The construction cost can further be broken down as follows:

- Membranes and Skid: $26 \%$

- Storage and Pump: $25 \%$

- Feed: $\quad 14 \%$

- Building: $10 \%$

- Cleaning: $2 \%$

- Instrumentation and Control: $5 \%$

- High-Pressure Pumping: $\quad 7 \%$

- Electrics: $4 \%$

- Pre-treatment and Post treatment: $\quad 8 \%$

The unit costs for process equipment decreases as the overall plant capacity increases due to economy of scale factors. The unit process equipment capital costs for a $20 \mathrm{mgd}$ plant is roughly two thirds that of a $1 \mathrm{mgd}$ plant (US \$1,49/gpd for a $1 \mathrm{mgd}$ plant vs. US \$1,00/gpd for a 20 mgd plant) (AWWA M46, 1999)

From a survey conducted in the USA for 22 brackish water treatment plants (AWWA M46, 1999: 5), the average operations and maintenance cost was US \$0,33 per 1000 litres (US \$1,28 per 1000 gallons) of permeate produced.

The operations and maintenance costs can be broken down as follows:

- $\quad$ Management: $22 \%$ (3.2 persons per $1 \mathrm{mgd}$ capacity)

- Power: $33 \%$

- Chemicals: $16 \%$

- Maintenance: $7 \%$

- $\quad 22 \%$ (including membrane replacement)

For a brackish water source $(<2000 \mathrm{mg} / \mathrm{l} \mathrm{TDS})$, ED/EDR and low-pressure reverse osmosis have very competing power consumption rates at around $1,3 \mathrm{kWh} / 1000$ litres $(4,9 \mathrm{kWh} / 1000$ gallons).

The motivation for this research came from the global continuous need for several new desalination methods and also for the need to improve on existing desalination technologies to aid a major step-change in the overall cost of desalinated water to make it viable not only for potable use, but also for industrial and agricultural uses as well.

There are also various practical problems with the conventional activated carbon capacitive deionization systems, one of the major one being significant fractions of the carbon surface which maybe occluded in the electrodes that use various binders. Furthermore the chances of chemical attack and various other problems are more in this case. This has motivated for an advanced research in this aspect leading to a more safe and a high surface area electrode for the removal of ions in a capacitive deionization system. Further the studies were done concentrating on the development of electrodes which uses zero binders and also with high porosity for the absorption of the ions from the water in capacitive deionization. Lack of research in this field and high demand for the water in the recent has called for further research in this field.

\section{Materials And Methods}

The development (designing, engineering and manufacturing) process was completed in three phases.

Phase 1: Electrode Manufacturing Process Development.

The stages for the development of carbon aerogel electrodes are mentioned below.

Stage 1: Polymerization

Stage 2: Pyrolization

Stage 3: Cell Assembly

Phase 2: Cell/Module Manufacturing Process Development. 
Stacking carbon aerogel electrodes and their associated electrical bus connections inside housing was the method used to manufacture the prototype unit. Maintaining to a simple manufacturing process was an objective. This prototype used stainless steel bus connections. Bus connections are the electrical connections to the electrode, dictating to the electrode to function as a cathode or anode. The high electrical currents and high salinity of the electrolytes are believed to create a very corrosive environment, even for stainless steel.

Phase 3: Control System Development.

It is very important to develop a control system to operate the prototype after the successful manufacturing of a prototype unit. The control system should be planned such a way so as to have a basic two flow path system, 'a single through state' and 'a recycle state'. Figure 1 illustrates the overall control system set-up used for the prototype water treatment evaluation test runs. A Direct Current (DC) power supply was connected to the cathode and anode connections of the prototype from a rectifier. The basis of all test runs was to monitor conductivity change of a metered feed stream, and the associated voltage and current requirements as a function of time.

An intact record of Voltage and current as a function of time was noted down during the trial run of the experiment. Once data has been recorded; a mass and energy balance was performed to determine the following main evaluation criteria:

- The quantity of ions adsorbed and at what rate (water production rate)?

- The quantity of energy required to absorb the ions?

Application of an automatic control console will make the process of switching from single through state to recycle phase easier. Cutting the DC power to the console and shorting the cathode and anode terminals, while a rinse stream was pumped through the cell, stopped an operational cycle and started a rinse cycle. Conductivity probes at the cell inlet and outlet ports were used to measure and record conductivity data. From the research observation and data's recorded until now lead us to design a plan for the future industrial scale capacitive deionization technology.

The end result of completing the above mentioned three phases was an operating industrial prototype system, ready for more intensive water treatment testing.

\section{Results}

An innovative resorcinol formaldehyde carbon aerogels were developed. It should be noted that the subsequent explanation of the manufacturing process is not mentioned in this Journal; a lot more advanced and innovative data was developed during this research episode, but this data's could not be published in this thesis due to the propriety nature of the technology and its scope for patency.

The foundation for the development of this carbon aerogels are from the resorcinol - formaldehyde (RF) combination followed by many subsequent steps. The developed electrodes were evaluated for its quality and efficiency. The electrodes were fixed in a prototype following the concepts of any other CDI technology. The arrangement of the developed electrodes is shown in figure 2.

In the above figure 2 the electrodes are placed between Anionic and Cationic exchange membranes. This is to fasten the movement of the charged ions towards the respective membranes from the water stream. During the stacking of electrodes for the initial evaluation phase no anionic or cationic membranes were used. The electrodes were stacked in prototype with passages for the movement of water through the electrodes. In the initial design of the prototype the brine solution was fed in to the prototype from the side and was collected from the top through the hole made at the centre of the electrodes, this way the water cannot escape the chamber without coming in contact with the electrodes and is considered to be the most ideal design when experimenting with lesser number of electrodes. The electrodes were connected to a stainless steel bus bar for the current supply to the electrodes. Each electrode is sandwiched by the current collectors for the equal supply of current throughout the electrodes. In this case we have utilised a graphite sheets as the current collector. Each electrode was separated by a spacer so as to prevent the short circuiting of the set-up. The spacers are made up of porous material so as to pass the water through them. The stacking set-up of electrodes is shown below in figure 2 .

Initially batch experiments were conducted on a 6 pair of electrodes which was stacked in a test module. The electrical connections were given to the batch set-up and the experiment was initiated. It was observed that there was a slight current variation initially but was terminated after sometime, the current collectors did not draw any current at a given voltage of $1.6 \mathrm{v}$ after a particular time period.

It was concluded that the current collectors did not draw any current because the volume of the water between the electrodes need to be replenished to obtain a reliable result which led us to the idea of continuous flow through model. Batch experiments did not show any noticeable results as the water circulation between the 
electrodes were highly minimised.

A continuous flow model makes use of a peristaltic pump for the supply of water between the electrodes. The test module was designed such a way it was made sure that every inlet supply of water comes in contact with the electrodes and was flushed out of the module after a particular time period. The peristaltic pump was attached to the prototype to force the water into the module and also to extract the same. Parallel type connection was instituted to be the best optimum connection for this set-up, it was found that a parallel type connection was able to supply equal voltage to the each and every electrodes

The stacked electrodes were fixed in the designed module, the pumps were connected and set to 75 runs per minute. The voltage was fixed at $1.8 \mathrm{v}$ and the inlet solution of TDS $2.17 \mathrm{ppt}$ was prepared and pumped into the module. The following trials run data's were obtained and was recorded graphically as in figure 3 .

It can be seen from the above data that the trial began with the initial TDS of $2.17 \mathrm{ppt}$ and within a time period of 18 minutes the TDS reduced drastically from $2.17 \mathrm{ppt}$ to $2.06 \mathrm{ppt}$ before the polarity reversal (BPR). It was evident that the ion adsorption from the water stream was occurring with just 5 pairs of electrodes of total surface area $240 \mathrm{~m}^{2}$. It was calculated from the above data that there was a reduction of $110 \mathrm{ppm}$ using $240 \mathrm{~m}^{2}$ area of the electrodes ie; for each $\mathrm{m}^{2}$ area of the electrodes $0.5 \mathrm{ppm}$ of electrodes were adsorbed. While incase of available CDI technology, per $\mathrm{m}^{2}$ area of electrodes absorbs only $0.031 \mathrm{ppm}$ of ions theoretically. This proves that the newly developed electrodes are much more efficient than the already available electrodes of the CDI technology.

After the adsorption cycle was completed the ions were desorbed back into the solution after the polarity reversal. The TDS of the water shooted up from 2.06 to 2.15 ppt until it was completely desorbed and the adsorption cycle was resumed. It is evident from the data that the ion adsorption was successful in the second attempt. The TDS reduced from 2.15 to 2.08 ppt. Hence proving that the newly developed electrodes absorbs ion more effectively than the available electrodes.

The ion adsorption was confirmed by another theory. It is known that more the number of ions in a solution more are the current passage through them and vice versa. A current v/s TDS graph fig 4 was plotted to reassure this concept.

It is evident from figure 4 that there was ion adsorption in the electrodes. The current levels reduced drastically to 0 amps indicating that the electrodes were saturated with ions and no more ions could be adsorbed until a desorption cycle was performed. It was also clear from the graph that after the polarity reversal (APR) the current shooted up and was reduced again to 0 amps.

Figure 5 illustrates the results of an energy requirement test run conducted. The energy was calculated by multiplying voltage and current data. The energy requirement graph plotted above against the data obtained explains a typical CDI module, due to the capacitive behaviour of the module. As the capacitors charge up, less and less current is allowed to flow through the capacitors, resulting in the typical exponential decrease of the required energy. Saturation of the electrode surface is directly proportional to the overall 'charged state' of the various capacitors making up a CDI module. Therefore a fully charged CDI module indicates a saturated electrode condition and vice-versa.

\section{Discussion And Conclusions}

$>$ It is possible to develop a carbon aerogel which is highly cost effective. An innovative electrode manufacturing technique has been developed. Future carbon aerogels will be even more human and environmental friendly as material science advances.

$>$ CDI uses electric regeneration, thereby wiping off the chances for the need to handle chemical waste streams. High concentrated reject water is the only waste stream produced. High recovery capacity of this technology eases the disposal problems of the high concentrated brine solution.

$>$ The newly developed electrodes were found to be more efficient and cheaper than the available electrodes of the existing CDI technology. The absorption capacities of the electrodes were found to be more than the existing electrodes, proving the chances of higher BET for the developed electrodes.

Thus simple design requirements and low energy costs makes the CDI technology highly competitive to the existing membrane technology like reverse osmosis for brackish water treatment in the near future. Capacitive Deionization is a young, but very promising technology for desalination of brackish and sea water sources.

\section{Acknowledgements}

I am very thankful to the Thermax Limited, Pune for giving me the opportunity to do my project work in their organization. I would like to express special thanks Dr.V.Kalyan Raman, Divisional Manager \& head, Centre of Biotechnology \& Water and wastewater technology, Thermax India Ltd., Pune and also Mr.Shiva.K.Varigala, Technologist, Thermax Limited, Pune for mentoring me throughout the course of the project work. 
I would like to express my deep sense of gratitude to Dr. A.Ganesha, Professor, Department of Civil Engineering, MIT, Manipal for their supervision, moral support and professional inputs at every stage of the project.

I wish to thank Dr. Narayana Shenoy, Professor Head, of the Civil Engineering Department, MIT, Manipal and all faculty members of the Civil Engineering Department, MIT, Manipal for their timely help and encouragement throughout the project for providing all facilities to make this project a success. Last but not the least my parents and relatives for being with me during the most difficult times of my life.

\section{Reference}

[1]. AMERICAN WATER WORKS ASSOCIATION (1999). Reverse Osmosis and Nanofiltration. Manual for Water Supply Practices M46. AWWA

[2]. ATLAS ROBERT (2007). Purification of Brackish Water using Hybrid CDI-EDI Technology. Aqua EWP, LLC.

[3]. DIETZ, S. (2004). Improved Electrodes for Capacitive Deionization. TDA Research, Inc.http://www.tda.com/Library/docs/Electr_Dietz_NSF_04_Proc.pdf Access: 23 August 2004

[4]. FARMER ${ }^{1}$, J (2000). Capacitive Deionization for the Elimination of Wastes. Strategic Environmental Research and Development Program. Livermore, CA: Lawrence Livermore National Laboratory.

[5]. FARMER ${ }^{2}$ J.C., FIX D.V., MACK G.V., PEKALA R.W., POCO, J.F. (1995). Capacitive Deionization with Carbon Aerogel Electrodes: Carbonate, Sulfate, and Phosphate. LLNL. Internet: http:/www.llnl.gov/tid/lof/documents/pdf/228237.pdf .Access: 12 September 2003.

[6]. FARMER ${ }^{3}$, J.C., FIX, D.V., MACK, G.V, PEKALA, R.W., POCO, J.F. (1996). Capacitive Deionization of NH4ClO4 Solutions with Carbon Aerogel Electrodes. LLNL. Internet: http:/www.llnl.gov/tid/lof/documents/pdf/228511.pdf .Access: 12 September 2003

[7]. FARMER ${ }^{4}$, J.C., FIX, D., MACK, G., PEKALA, R., POCO, J. (1995). Capacitive Deionization of $\mathrm{NaCl}_{\text {and NaNO}}$ Solutions with Carbon Aerogel Electrodes. LLNL. Internet: http:/www.llnl.gov/tid/lof/documents/pdf/227653.pdf .Access: 12 September 2003

[8]. FARMER ${ }^{5}$ J.C., J.K., PEKALA R.W., FIX D.V., MACK G.V, POCO J.F., GRANT W.J., POMERNACKI C.L., SAVOYE C.F. (1995). Capacitive Deionization with Carbon Aerogel Electrodes. LLNL. Internet: http:/www.llnl.gov/tid/lof/documents/pdf/226878.pdf .Access: 12 September 2003.

[9]. FARMER ${ }^{6}$ J.C., TRAN T.D., RICHARDSON J.H., FIX D.V., MAY S.C., THOMSON S.L. (1997). The Application of Carbon Aerogel Electrodes to Desalination \& Waste Treatment. LLNL. Internet: http:/www.llnl.gov/tid/lof/documents/pdf/231717.pdf .Access: 17 September 2003.

[10]. FARMER ${ }^{7}$ J.C., FIX D.V., MACK G.V., POCO J.F., NIELSEN J.K., PEKALA R.W., RICHARDSON J.H. (1995). Capacitive Deionization of Seawater. LLNL.Internet: http:/www.llnl.gov/tid/lof/documents/pdf/121958.pdf .Access: 17 September 2003.

[11]. FARMER ${ }^{8}$ J.C., RICHARDSON J.H., FIX D.V., DE PRUNDA J.A.H., MACK G.V.,

[12]. POCO J.F., NIELSEN J.K., PEKALA R.W. (1996). Capacitive Deionization System. LLNL. Internet: http:/www.llnl.gov/tid/lof/documents/pdf/231565.pdf . Access: 12 September 2003.

[13]. KWANG-KYU PARK, JAE-BONG LEE, PILL-YANG PARK, SEOK-WON YOON, JEON-SOO MOON, HEE-MOON EUM, CHI-WOO LEE (2006) Development of a Carbon Sheet Electrode for Electrosorption Desalination. 